\title{
AUTONOMIA FINANCEIRA LOCAL E DEMOCRACIA
}

\section{LOCAL BUDGETARY AUTONOMY AND DEMOCRACY}

Sérgio Assoni Filho*

\begin{abstract}
Resumo:
Este artigo contém reflexões sobre a importância da descentralização fiscal na implementação da forma democrática de Governo, em particular, ressaltando o potencial da participação popular na racionalização da gestão financeira estatal realizada no âmbito local. Para tanto, o autor analisa criticamente o federalismo fiscal brasileiro, sugerindo mudanças em nossa ordem jurídica capazes de promover, de fato, a autonomia financeira dos entes subnacionais.

Palavras-chave: Autonomia financeira. Descentralização fiscal. Federalismo fiscal. Emancipação municipal. Participação popular. Controle social. Democracia.
\end{abstract}

\begin{abstract}
:
This article brings reflections about the importance of tax decentralization in the enforcement of democratic government form, in particular, highlighting the potential of popular participation in the rationalization of tax management in local area. The author critically analyses the Brazilian Tax Federalism, by the suggestion of legal changes to promote definitively the tax autonomy of subnational entities.
\end{abstract}

Keywords: Tax autonomy. Tax decentralization. Tax Federalism. Municipal Emancipation. Popular participation. Social Controls. Democracy.

Há tempos, existem pensadores que identificam a forma democrática de Governo com a idéia de descentralização do poder político, ${ }^{1}$ acreditando que a diluição da autoridade estatal pode ser mais proficiente não-só no combate ao arbítrio governamental, mas também por tornar os atos e decisões oriundas deste poder mais à medida dos cidadãos, uma vez que a descentralização proporciona a aproximação entre governantes e governados.

A atualidade desse entendimento fica evidenciada quando se tem em vista a evolução da concepção de Governo democrático, baseada na participação do cidadão na definição do interesse público, ao invés do processo decisório governamental ser realizado exclusivamente pelas estruturas burocráticas do Estado e à revelia da sociedade.

Em tal direção, nas modernas sociedades de massa, a participação dos cidadãos se presta ao direcionamento da atuação do Estado-Administração, pois o

\footnotetext{
Doutor e Mestre em Direito Econômico-Financeiro pela Faculdade de Direito da Universidade de São Paulo. Cf. TOCQUEVILLE, Alexis de. A democracia na América. Tradução de Eduardo Brandão. São Paulo: Martins Fontes, 1998. p. 102-103 (redigido originalmente entre maio de 1831 e fevereiro de 1832); MILL, John Stuart. Considerações sobre o governo representativo. Tradução de Manoel Innocêncio de Lacerda Santos Júnior. Brasília: Editora Unb, 1981. p. 155 (editado originalmente em 1861).
} 
isolamento gestor pode conduzir à tomada de decisões que estejam em descompasso com a já enorme, e ainda crescente, gama de apelos sociais.

A nosso juízo, a participação popular na gestão da coisa pública ganha efetividade a partir do âmbito local, pois o cidadão comum conhece amplamente seus problemas cotidianos, justamente por sentir na pele os seus reflexos, sendo perfeitamente capaz de opinar sobre suas reais necessidades e de sugerir alternativas, uma vez que o legítimo Governo democrático é aquele cuja atuação oferece resposta adequada às carências e preferências da coletividade.

Por essa razão, é imperativo que a sociedade civil se mobilize e faça valer a faculdade que lhe é conferida pela admissibilidade jurídica da participação popular na gestão pública, é dizer, as organizações sociais devem esgotar essa dimensão participativa, sempre que houver sua institucionalização em cada esfera governamental.

Ressaltando que a descentralização do poder político deve vir acompanhada da correspondente descentralização de recursos financeiros, em um montante compatível com o atendimento das necessidades populares externadas, pois a inexistência deste mínimo substrato material tolhe qualquer intento participativo.

Com o escopo de democratizar o exercício do poder político, após décadas de autoritarismo, nossa Constituição vigente delineou uma forma federativa de Estado que pudesse munir os âmbitos regional e local de poder de auto-organização, descentralizando competências administrativas e legislativas.

Além disso, a Magna Carta procurou dar concreção à mencionada descentralização, pois aliada à autonomia política e administrativa conferida aos entes federativos, buscou dotá-los dos recursos financeiros suficientes à consecução de suas atribuições, isto é, a autonomia de cunho financeiro das unidades subnacionais também foi uma preocupação constante de nosso legislador constituinte.

Aliás, essa é a atual tendência verificada nos países latino-americanos em desenvolvimento, que têm em comum um passado de governos ditatoriais e que têm por meta a consolidação de suas democracias, conforme a análise de José Roberto Rodrigues Afonso e Thereza Lobo:

A observação recente das experiências latino-americanas permite identificar uma tendência clara de avanço na descentralização fiscal diretamente proporcional à consolidação do regime democrático na região. (...) De certa forma, há uma idéia genérica aqui enunciada de modo simplório, de que a democracia exige autonomia e fortalecimento político e financeiro, seja dos Poderes 
Legislativo e Judiciário, seja das esferas subnacionais de governo. ${ }^{2}$

No mais, o controle social adquire vitalidade quando exercido na localidade, pois se a unidade subnacional possui, de fato, autonomia política, administrativa e financeira, a atuação governamental deve ser estritamente condizente com as aspirações coletivas, ficando facilitado seu monitoramento, devido à visibilidade decorrente da maior proximidade entre Administração Pública e cidadão-administrado.

Disso resulta a associação entre democratização e descentralização, especialmente de índole fiscal, uma vez que a descentralização de recursos é um dos mecanismos aptos à garantia da autonomia financeira das entidades subnacionais, sem a qual permanece inócua a participação da sociedade civil no processo decisório governamental de âmbito local.

1. Descentralização fiscal e autonomia subnacional em nossa ordem jurídica

Conforme a clássica lição de Montesquieu, a forma federativa estatal é caracterizada por uma convenção pela qual diversos corpos políticos concordam em se tornarem cidadãos de um Estado maior, que querem formar, constituindo uma verdadeira sociedade de sociedades. ${ }^{3}$

Nessa direção, o federalismo pode ser entendido, segundo a lição de Antônio Roberto Sampaio Dória, como "a fórmula histórico-programática de composição política que permite harmonizar a coexistência, sobre idêntico território, de duas ou mais ordens de poderes autônomos, em suas respectivas esferas de competência". ${ }^{4}$

O nosso País adotou a forma federativa de Estado, o que está expresso no caput do art. $1^{\circ}$ da Constituição vigente, ${ }^{5}$ consagradora da existência de três esferas governamentais, a saber: a federal, a estadual, e a municipal.

Dessa maneira, a Constituição Federal, de 1988, veio reforçar uma tradição municipalista brasileira, inovando ao implantar entre nós um federalismo composto por três esferas governamentais, no intento de promover a democratização mediante a

2 AFONSO, José Roberto Rodrigues; LOBO, Thereza. Descentralização fiscal e participação em experiências democráticas retardatárias. Disponível em: < http: // www.federativo. bndes.gov.br >. Acesso em: 30 jan. 2002.

3 MONTESQUIEU. Do espirito das leis. Tradução de Fernando Henrique Cardoso. São Paulo: Difusão Européia do Livro, 1962. v. 1, p. 155.

4 DÓRIA, Antônio Roberto Sampaio. Discriminação de rendas tributárias. São Paulo: Bushatsky, 1972. p. 9.

5 Conforme o caput do art. $1^{\circ}$ da Constituição vigente: “A República Federativa do Brasil, formada pela união indissolúvel dos Estados e Municípios e do Distrito Federal, constitui-se em Estado Democrático de Direito (...)." 
descentralização do poder político, em tal sentido, contrastando com os nossos paradigmas constitucionais anteriores.

A nossa Magna Carta estabelece que a organização político-administrativa estatal compreende a União, os Estados, o Distrito Federal e os Municípios, todos autônomos nos termos de seu texto (art. 18), possuindo os entes federativos descentralizados competências administrativas e legislativas próprias.

O texto constitucional pátrio também determina que a forma federativa do Estado brasileiro não será objeto de emenda tendente à sua abolição, configurando assim cláusula constitucional pétrea (art. $60, \S 4^{\circ}, \mathrm{I}$ ), de modo que qualquer atuação dos Poderes Executivo e Legislativo da União na direção de uma centralização de competências e recursos, até então circunscritos às esferas de poder estadual e municipal, evidenciará a ocorrência de inconstitucionalidade.

Ressaltando que a forma estatal federal surgiu nos Estados Unidos daAmérica, em 1787, como fruto da união das treze colônias inglesas, contudo, em muito diferindo da experiência federativa pátria, uma vez que aquela foi o resultado da evolução histórica e do amadurecimento das instituições políticas e sociais, originando-se de uma agregação, em que os entes envolvidos possuíam, de fato, autonomia política, administrativa e financeira, mas decidiram ceder parte de suas prerrogativas para consolidarem um único Estado, que melhor pudesse lutar pela consecução de seus interesses comuns. Assim sendo, desse sentimento de unidade nasceu o modelo federativo dos Estados Unidos da América, por tal razão, também chamado de centrípeto.

No caso do Brasil a adesão à forma federativa de Estado aconteceu com a Proclamação da República, em 1889, mas por meio de um processo inverso de segregação, pois havia um poder central que se fragmentou, daí ser reconhecido nosso federalismo como centrifugo, sendo as entidades subnacionais criadas, de certa forma, artificialmente, sem que houvesse um sentimento nacional ou uma natural evolução histórica das instituições regionais e locais.

Assim sendo, o federalismo brasileiro ainda está longe da perfeição, até por ter sido resultante "mais de uma experiência científica do que de uma experiência prática", ${ }^{6}$ mostrando-se frágil e incompleto desde as suas origens, pois vários entes da federação não dispunham das mínimas condições materiais necessárias à manutenção do status de entidade autônoma.

Disso resultando a ocorrência de problemas crônicos que têm profundos reflexos na atualidade, inclusive por conseqüência do nosso modelo federativo ser marcado pela heterogeneidade das entidades subnacionais que o integram, uma vez que o País

\footnotetext{
6 Cf. GOLDSCHMIDT, Fábio Brun. Críticas à discriminação de rendas tributárias e à federação brasileira. Revista Tributária e de Finanças Públicas, v. 8, n. 35, nov./dez. p. 2000. p. 71.
} 
possui dimensões continentais e uma acentuada diversidade social, econômica, cultural, histórica, política, climática etc. ${ }^{7}$

Em um Estado federal heterogêneo como o brasileiro, em que cada ente federativo tem uma realidade distinta, principalmente no que toca ao aspecto financeiro, é comum às entidades subnacionais o recebimento de tarefas desproporcionais aos recursos para a sua execução, verificando-se neste caso a ocorrência de uma "crise de sobrecarga", ou seja, de um "desequilíbrio entre as obrigações e os meios financeiros". ${ }^{8}$

Até porque, os dispositivos constitucionais que tratam da repartição das receitas tributárias são suficientemente precisos, enquanto os dispositivos constitucionais que se referem à distribuição dos encargos são demasiadamente vagos, motivando ora um jogo de "empurra-empurra" entre os entes federados, ora uma superposição de ações. ${ }^{9}$

Tendo em mira a ampla diferenciação subnacional denunciada pela realidade fática, a Magna Carta é de importância primordial ao pretenso equilíbrio federativo, na qualidade de ordem jurídica comum e responsável pelo estabelecimento das regras que permitirão a melhor composição política da pluralidade de esferas governamentais existentes.

Dessa maneira, incumbe à Constituição Federal tornar harmônica a coexistência territorial das diversas ordens de poderes autônomos, de acordo com as respectivas competências fixadas em seu próprio texto, servindo os dispositivos constitucionais como sede irradiadora dos poderes e da capacidade de auto-organização dos entes descentralizados, em particular, proporcionando-lhes o mencionado substrato material mínimo, sem o qual não se pode falar em "autonomia subnacional”, implícita à idéia de Estado federativo.

Nessa direção, Manuel De Juano argumenta que a descentralização apenas pode ser considerada harmoniosa quando os governos locais contarem com recursos financeiros suficientes à cobertura de seus gastos públicos, isto é, quando tiverem à sua disposição os meios materiais necessários à concretização de seus fins, o que, deste modo, permitiria sua maior aproximação com a idéia de democracia. ${ }^{10}$

Em tal direção, preconizando a descentralização fiscal como desejável à racionalização alocativa em um contexto federativo, o parecer de Carlos Alberto Longo e Roberto Luis Troster:

\footnotetext{
Vide o artigo: GUIMARÃES NETO, Leonardo. Desigualdades e politicas regionais no Brasil: caminhos e descaminhos. Disponível em: <http://www.federativo.bndes.gov.br>. Acesso em: 18 fev. 2002.

8 Cf. TORRECILLAS RAMOS, Dircêo. O federalismo assimétrico. São Paulo: Plêiade, 1998. p. 88.

9 Cf. SERRA, José; AFONSO, José Roberto. Federalismo fiscal à brasileira: algumas reflexões. Disponível em: <http:// www.federativo.bndes.gov.br>. Acesso em: 30 jan. 2002.

${ }^{10}$ DE JUANO, Manuel. Curso de finanzas y derecho tributario. Rosario: Molachino, 1964. v. 3, p. 273.
} 


\begin{abstract}
A limitação espacial da incidência dos benefícios das despesas públicas requer, por razões de eficiência, uma estrutura fiscal descentralizada, cabendo a cada governo jurisdições de diferentes tamanhos, dentro das quais o nível e a composição dos serviços públicos seriam determinados e financiados. Então, uma justificativa econômica para o sistema federal é baseada, essencialmente, na capacidade que unidades de governos descentralizados têm para melhorar a alocação de recursos do setor público, através da diversificação dos serviços públicos de acordo com as preferências locais. ${ }^{11}$
\end{abstract}

Diante da observação de nossa Carta constitucional vigente, pode-se dizer que o ordenamento jurídico brasileiro tem nítida inclinação à promoção da autonomia dos entes federativos locais, especialmente no que tange ao aspecto financeiro, pois as unidades subnacionais municipais foram dotadas não-só de competências administrativas e legislativas próprias, mas também houve um esforço do constituinte originário em provê-las dos meios materiais indispensáveis à consecução das finalidades inerentes a seus desígnios.

Até porque, ausentes os recursos financeiros necessários ao atendimento das atribuições erigidas no texto magno, os entes descentralizados jamais poderão levar a cabo o ideal de autodeterminação, visto que somente a autonomia financeira, em um contexto federativo, pode preservar o Governo local de um verdadeiro estado de inanição decisória, capaz de demover qualquer possibilidade de efetividade autonômica, uma vez que o ente federativo local torna-se refém de uma delicada ciranda de negociações políticas, em nome da incessante busca de recursos junto às demais esferas governamentais.

Com fundamento na enfática afirmação de José Maurício Conti:

A autonomia financeira é de fundamental importância. Não é exagero dizer ser ela quem garante a sobrevivência da federação. Sem recursos para se manter, as entidades federadas estão fadadas ao fracasso. Não poderão exercer as funções que lhe competem, e passarão a depender do poder central para financiar suas atividades, circunstância que aniquila todo e qualquer poder autônomo que se lhes atribua. $^{12}$

Por esse motivo, o ordenamento jurídico brasileiro procura assegurar a mencionada autonomia financeira de todas as entidades subnacionais oriundas de nosso federalismo e, tendo em vista que a Federação brasileira é caracterizada pela existência

\footnotetext{
${ }^{11}$ LONGO, Carlos Alberto; TROSTER, Roberto Luis. Economia do setor público. São Paulo: Atlas, 1993. p. 148 .

${ }^{12}$ CONTI, José Maurício. Federalismo fiscal e fundos de participação. São Paulo: Juarez de Oliveira, 2001. p. 14.
} 
de três esferas governamentais, também há preocupação do legislador pátrio em garantir a existência de recursos materiais suficientes às atribuições dos entes descentralizados de âmbito local, os Municípios, que são nada mais que a manifestação cotidiana do poder político estatal, devido a sua maior proximidade com os cidadãos.

Até porque, no dizer de Jean Cluzel:

A perspectiva de Municípios realmente autônomos administrativamente, tecnicamente e financeiramente - supõe um Estado descentralizado em que a unidade nacional seria garantida pela coesão social, mas também pela vitalidade das células de base que são as coletividades locais. Quando o Município está em perigo, é também a República que está em perigo. Inversamente, o que serve e vivifica o Município, serve e vivifica a República. ${ }^{13}$

A Constituição Federal brasileira reconhece plenamente a autonomia dos Municípios, conferindo-lhes titularidade no que concerne aos direitos de auto-organização de cunho político-administrativo (art. 18), garantindo que eles terão uma espécie de "Constituição" própria, chamada de Lei Orgânica, por meio da qual terão capacidade de deliberação sobre os assuntos correspondentes às suas respectivas competências, que, aliás, também vêm fixadas no texto constitucional (arts. 29 e 30).

Quanto ao aspecto financeiro, a Magna Carta determina que os Municípios disporão de fontes próprias de recursos (arts. 145, 149, § $1^{\circ}$ e 156), assim como receberão recursos originários da arrecadação realizada pelos outros entes federativos (arts. $158 \mathrm{e}$ $153, \S 5^{\circ}, \mathrm{II}$ ), além dos recursos provenientes dos fundos de participação (art. 159).

Ressaltando que o art. 30, inciso III, da Constituição Federal brasileira determina que cabe aos Municípios a instituição e arrecadação dos tributos de sua competência, assim como a aplicação das rendas auferidas, de modo que o ente federativo local tem possibilidade de organizar, nas palavras de Heleno Taveira Torres, "um sistema financeiro próprio, autônomo, protegendo-se politicamente ante os Estados e a União". ${ }^{14}$

Com relação à discriminação de rendas pelas fontes de arrecadação, conforme o disposto na Constituição, em seus arts. 145 e 156, os Municípios podem instituir taxas e contribuições de melhoria, bem como os impostos que incidam sobre a propriedade predial e territorial urbana (IPTU), a transmissão inter vivos de bens imóveis (ITBI) e os serviços de qualquer natureza (ISS), além de poderem instituir a contribuição cobrada de

\footnotetext{
${ }^{13}$ CLUZEL, Jean. Finances publiques e pouvoir local. Paris: Librairie Générale de Droit et de Jurisprudence, 1980, p. 25.

14 TORRES, Heleno Taveira. La autonomía financiera de los municipios en el derecho brasileño. Revista Argentina de Derecho Tributario, n. 4, out./ dez. p. 2002. p. 975.
} 
seus servidores e destinada aos seus sistemas de previdência e assistência social, de acordo com a inteligência do art. $149, \S 1^{\circ}$.

Já no que diz respeito à discriminação de rendas pelo produto da arrecadação, o texto constitucional estabelece que os Municípios terão as seguintes participações no que for arrecadado pelos outros entes federativos:

a) a totalidade do que for arrecadado pela União a título de imposto de renda e proventos de qualquer natureza - IR, incidente na fonte, sobre rendimentos pagos por eles, suas autarquias e fundações (artigo 158, I);

b) cinqüenta por cento do que for arrecadado pela União a título de imposto sobre os imóveis situados em propriedade territorial rural - ITR (artigo 158, II);

c) cinqüenta por cento do que for arrecadado pelo Estado a título de imposto sobre a propriedade de veículos automotores licenciados em seus territórios - IPVA (artigo 158, III);

d) vinte e cinco por cento do que for arrecadado pelo Estado a título de imposto sobre operações relativas à circulação de mercadorias e sobre as prestações de serviços de transporte interestadual e intermunicipal e de comunicação - ICMS, observados os critérios de repartição deste valor (artigo 158, IV e $\S$ único);

e) setenta por cento do que for arrecadado pela União a título de imposto sobre operações com base no ouro como ativo financeiro - IOF (artigo 153, § $5^{\circ}$, II).

Os entes federativos locais também receberão recursos provenientes de fundos, dos quais se destaca o Fundo de Participação dos Municípios, em que a União entregará aos Municípios vinte e dois e meio por cento do que ela arrecadar a título de imposto sobre a renda e proventos de qualquer natureza - IR, bem como do que ela arrecadar a título de imposto sobre produtos industrializados - IPI (art. 159, I, b).

Além dessas transferências financeiras de caráter compulsório, os Municípios ainda podem receber transferências voluntárias de recursos das outras unidades subnacionais, desde que observado o disposto na legislação infraconstitucional, com destaque para o que determina a Lei n. 4.320, de 17 de março de 1964, assim como o estabelecido na lei complementar n. 101, de 04 de maio de 2000, conhecida esta última como Lei de Responsabilidade Fiscal.

Assim sendo, nosso ordenamento jurídico procura assegurar a autonomia financeira das entidades subnacionais de âmbito local, utilizando uma ampla gama de mecanismos legais que objetivam alcançar tal escopo, conferindo aos Municípios fontes próprias de recursos, seja por meio de vinculações, participações e transferências, seja pela administração de fundos. 
A partir da consecução dessa autonomia financeira local, o Município pode ser verdadeiramente identificado com uma partícula de poder do Estado-Administração, de acordo com o enunciado por Emanuele Morselli, pois, para ele, o ente local é:

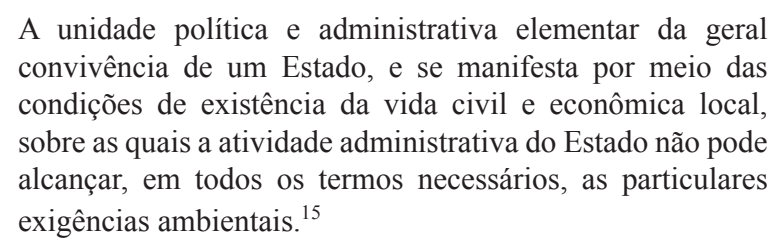

Em tal perspectiva, da descentralização fiscal promovida pela nossa ordem jurídica, dotando regularmente os Municípios dos meios materiais necessários ao atendimento dos particulares anseios da população local, pode emergir uma gestão da coisa pública marcada pela implementação da participação popular, que somente a autonomia financeira local é capaz de propiciar ou, ao menos, potencializar, como veremos na seqüência deste estudo.

\section{A participação popular na gestão das finanças locais}

Hodiernamente, ganhou vulto a concepção de que a aplicação conjunta do modelo democrático representativo com o exercício da democracia direta seria uma alternativa viável ao aprimoramento da forma democrática de Governo, deste modo, proporcionando a ampliação da participação popular na gestão da coisa pública, a fim de promover uma verdadeira disseminação dos centros decisórios do poder político.

Conforme o parecer de Eduardo García de Enterría:

As eleições, que são, sem dúvida, capitais para a democracia, como procedimento instrumental da expressão da confiança popular, não conseguem, sem embargo, absorver a plenitude desta, a qual é imprescindível que se mantenha viva durante todo o período de gestão, como o nervo que vivifica e anima a atuação dos gestores e, com ela, todo o sistema democrático. $^{16}$

A efetiva participação cidadã no exercício do poder estatal resulta em uma diafanidade decisória, que tem íntima relação com a idéia de descentralização, uma vez que a atuação governamental de âmbito local tem reflexos imediatos na rotina diária da população, permitindo o seu constante monitoramento por parte dos cidadãos.

${ }^{15}$ MORSELLI, Emanuele. Compendio di scienza delle finanze. 21. ed. Padova: CEDAM, 1952. p. 323.

${ }^{16}$ GARCÍA DE ENTERRÍA, Eduardo. Democracia, jueces y control de la administración. 5. ed. Madrid: Civitas, 2000. p. 103. 
Assim sendo, o controle social não-só é exercido de maneira mais profícua na gestão pública local, mas também se presta à ampliação da participação popular, mediante a contínua mobilização dos segmentos sociais, a fim de evidenciar suas carências e prioridades junto aos poderes instituídos, de modo que tais interesses estejam sempre presentes na pauta das deliberações políticas, bem como causem impacto no processo decisório governamental.

Segundo o entendimento de Dinorá Adelaide Musetti Grotti:

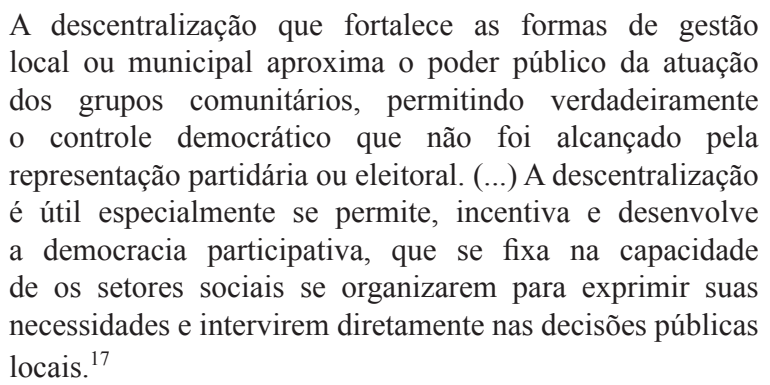

A submissão da gestão financeira local à sociedade propriamente dita é talvez a face mais importante desse atual processo de potencialização da democracia pela participação popular direta, visto que o controle social dos recursos públicos, inegavelmente, torna os governantes e os governados coadjuvantes no que diz respeito à determinação do destino destes meios materiais.

Dessa maneira, a descentralização fiscal derivada de nossa forma federativa de Estado tem uma relevância ímpar no referido processo de ampliação do cânone democrático, abrindo um leque de ocasiões consentâneas à participação cidadã na gestão pública, pois assegurar a autonomia financeira das entidades subnacionais locais é propiciar a aludida aproximação da população com as estruturas do poder estatal.

Também nessa direção, as palavras de José Luíz Quadros de Magalhães, ao se pronunciar a respeito da democracia participativa a partir do poder local:

Para nós, no Brasil, que não vivemos um Estado Social efetivo, que fosse capaz de oferecer saúde, educação e previdência de qualidade para todos, o caminho para a inclusão e efetiva participação do nosso povo como cidadãos é o da fragmentação coordenada do poder, a descentralização radical de competências, fortalecendo os

\footnotetext{
17 GROTTI, Dinorá Adelaide Musetti. Desafios da democratização da gestão local: a formulação do orçamento participativo. In: GARCIA, Maria. (Coord.). Democracia, hoje: um modelo político para o Brasil. São Paulo: Instituto Brasileiro de Direito Constitucional, 1997. p. 140.
} 
Estados e principalmente os Municípios, assim como tornar permeável o poder, com a criação de canais de participação popular permanentes. ${ }^{18}$

Desse modo, para que a administração do bem comum possa ser chamada de pública, na acepção da palavra, é preciso que ela seja colocada em prática não-só com o conhecimento de todos, mas também com a participação, efetiva ou potencial, de todos. $\mathrm{O}$ que fica francamente facilitado em se tratando de uma gestão circunscrita à localidade, portanto, desempenhada pelos gestores bem aos olhos da sociedade.

Consoante à lição de Norberto Bobbio:

Pode-se interpretar o ideal do governo local como um ideal inspirado no princípio segundo o qual o poder é tanto mais visível quanto mais próximo está. De fato, a visibilidade não depende apenas da apresentação em público de quem está investido no poder, mas também da proximidade espacial entre o governante e o governado. (...) A publicidade do governo de um Município é mais direta, e é mais direta exatamente porque é maior a visibilidade dos administradores e das suas decisões. ${ }^{19}$

Na nossa opinião, tal participação popular direta na gestão das finanças locais pode ser concretizada pela via orçamentária, uma vez que a realização de qualquer política pública, visando ao atendimento das pretensões sociais, demanda a aplicação dos meios materiais disponíveis em cada esfera governamental.

Como os recursos financeiros são sempre insuficientes à plena satisfação das necessidades da população, a participação cidadã é de fundamental importância na definição das prioridades alocativas, haja vista que, em uma forma democrática de Governo, as despesas públicas autorizadas nas leis orçamentárias devem refletir as aspirações coletivas, ficando o emprego destes escassos haveres, por parte do EstadoAdministração, balizado pelas escolhas populares.

Por essa razão, mostra-se perfeitamente oportuno o controle social orçamentário no âmbito local, funcionando a participação popular como instrumento de apuração do legítimo interesse público existente em tal esfera descentralizada do poder estatal, de maneira a servir de norte à atuação e à tomada de decisões governamentais no que toca à utilização daquele substrato material angariado junto ao meio social.

\footnotetext{
${ }^{18}$ MAGALHÃES, José Luíz Quadros de. O poder local no Brasil: a alternativa da democracia participativa. Disponível em: <http:// www.cadireito.com.br >. Acesso em: 18 set. 2005.

${ }^{19}$ BOBBIO, Norberto. O futuro da democracia: uma defesa das regras do jogo. Tradução de Marco Aurélio Nogueira. 7. ed. São Paulo: Paz e Terra, 2000. p. 102.
} 
Além disso, o advento do controle social orçamentário permite conferir visibilidade aos gastos estatais realizados, tendo em vista que os cidadãos poderão verificar continuamente se as suas preferências, expostas nas discussões e deliberações que antecederam a aprovação das leis orçamentárias municipais, têm ou-não correspondência com os investimentos efetuados, durante a execução orçamentária, pelos gestores públicos.

Assim sendo, em um Governo qualificado como democrático, os orçamentos públicos podem assegurar a transparência na gestão fiscal, na medida em que dão ensejo ao constante controle social da atividade financeira do Estado-Administração, no sentido de que qualquer cidadão pode averiguar se as finanças públicas locais estão sendo geridas de acordo com as diretrizes eleitas pela população, fruto de sua participação nas fases de discussão e deliberação dos projetos de leis orçamentárias municipais.

O referido controle social orçamentário está amplamente amparado pela nossa ordem jurídica vigente, pois ele decorre do exercício do direito de participação popular no planejamento e fiscalização da gestão municipal, em conformidade com os princípios constitucionais (art. $1^{\circ}, \S$ único, combinado com o art. 29 , inciso XII) ${ }^{20}$ e os dispositivos infraconstitucionais (art. 48, caput e $\S$ único, da Lei de Responsabilidade Fiscal e art. 44, do Estatuto da Cidade), ${ }^{21}$ munindo a sociedade de maior potencial de supervisão com relação à atividade financeira governamental de âmbito local.

Desse modo, o ordenamento jurídico brasileiro democratiza a destinação dos recursos financeiros, pois a consulta à população é condição prévia e obrigatória à aprovação das leis orçamentárias locais, cabendo à Administração Pública observar, quando da efetivação dos gastos governamentais, quais foram as prioridades alocativas eleitas pelos populares durante o planejamento municipal, devidamente materializadas no espectro orçamentário.

\footnotetext{
${ }^{20}$ De acordo com a inteligência dos mencionados dispositivos constitucionais: “Art. $\mathbf{1}^{\mathbf{0}}$. (...) Parágrafo único. Todo o poder emana do povo, que o exerce por meio de representantes eleitos ou diretamente, nos termos desta Constituição". "Art. 29. O Município reger-se-á por lei orgânica, (...) atendidos os princípios estabelecidos nesta Constituição, na Constituição do respectivo Estado e os seguintes preceitos: (...) XII - cooperação das associações representativas no planejamento municipal (...)".

${ }^{21}$ Assim dispõe a Lei de Responsabilidade Fiscal (lei complementar $n^{\circ}$ 101, de 04 de maio de 2000): "Art. 48. São instrumentos de transparência da gestão fiscal, aos quais será dada ampla divulgação, inclusive em meios eletrônicos de acesso público: os planos, orçamentos e leis de diretrizes orçamentárias; as prestações de contas e o respectivo parecer prévio; o Relatório Resumido da Execução Orçamentária e o Relatório de Gestão Fiscal; e as versões simplificadas desses documentos. Parágrafo único. A transparência será assegurada também mediante incentivo à participação popular e realização de audiências públicas, durante os processos de elaboração e de discussão dos planos, lei de diretrizes orçamentárias e orçamentos". Assim dispõe o Estatuto da Cidade (Lei n. 10.257, de 10 de julho de 2001): "Art. 44. No âmbito municipal, a gestão orçamentária participativa de que trata a alínea $f$ do inciso III do art. $4^{\circ}$ desta Lei incluirá a realização de debates, audiências e consultas públicas sobre as propostas do plano plurianual, da lei de diretrizes orçamentárias e do orçamento anual, como condição obrigatória para sua aprovação pela Câmara Municipal”.
} 
Em suma, o ordenamento jurídico pátrio está alinhado à emergência de uma espécie de paradigma democrático participativo, visto que promove a autonomia financeira local e, a partir dela, suscita a participação popular direta na gestão das finanças locais, especialmente por meio das leis orçamentárias municipais.

Contudo, se a descentralização de recursos financeiros engendrada pela nossa ordem jurídica permite tal evolução de índole democrática, ela também pode fomentar a perpetuação de relações clientelistas entre os entes federativos, em particular, quando levada a efeito em benefício de apelos oportunistas, sendo negligenciada a observância de critérios identificáveis com o escopo de viabilizar a efetividade autonômica subnacional.

Lamentável exemplo dessa perversa realidade é o das emancipações municipais ocorridas recentemente em nosso País, em sua grande maioria, realizadas sem qualquer comprometimento com a coisa pública, uma vez que motivadas exclusivamente pelo interesse de recebimento de repasses fiscais advindos de outras esferas governamentais, os quais vêm produzindo uma verdadeira crise sistêmica em nossa Federação, cuja coibição demanda o urgente aprimoramento da legislação referente à matéria, de acordo com o exposto a seguir.

\section{Emancipação local com racionalidade financeira}

Durante a vigência do regime constitucional anterior, com a redação que lhe deu a Emenda Constitucional n. 1/69, a Constituição Federal, de 1967, estabelecia, em seu art. 14, que a criação de novos Municípios dependeria da observância de requisitos mínimos de população e renda pública, ${ }^{22}$ uniformes em todo território nacional, nos moldes fixados pela Lei Complementar federal n. 1, de 09 de novembro de 1967, aplicada em conjunto com o Decreto-Lei Complementar n. 9, de 31 de dezembro de 1969. ${ }^{23}$

Com a promulgação da atual Constituição Federal, em 05 de outubro de 1988, essa conjuntura foi modificada profundamente, visto que a criação de novos

\footnotetext{
${ }^{22}$ A redação desse pretérito dispositivo constitucional era a seguinte: “Art. 14. Lei complementar estabelecerá os requisitos mínimos de população e renda pública, bem como a forma de consulta prévia às populações, para a criação de Municípios. Parágrafo único. A organização municipal, variável segundo as peculiaridades locais, a criação de Municípios e a respectiva divisão em Distritos dependerão de lei."

${ }^{23}$ Tal legislação infraconstitucional determinava como requisitos mínimos à emancipação municipal: a) população superior a dez mil habitantes ou que não seja inferior a cinco milésimos do Estado de origem; b) eleitorado que não seja inferior a dez por cento da população; c) centro urbano com o mínimo de duzentas casas; d) arrecadação mínima de cinco milésimos da receita estadual de impostos, apurada no exercício financeiro anterior à iniciativa emancipatória; e) ser distrito ou subdistrito a mais de quatro anos; f) possuir condições adequadas à instalação da Prefeitura e da Câmara Municipal; g) apresentar solução de continuidade de pelo menos cinco quilômetros entre seu perímetro urbano e o do Município de origem; h) não interromper a continuidade territorial do Município de origem; i) a proposta emancipatória só poderia ser feita quadrienalmente, no ano anterior ao da eleição municipal.
} 
Municípios, prevista no $\S 4^{\circ}$ de seu art. 18, passou a ser regida pela esfera estadual, sendo-lhe transferida a competência para editar lei que fixasse os requisitos mínimos à emancipação. ${ }^{24}$

Aparentemente, essa mudança representou uma franca tentativa do constituinte originário de preservar a autonomia recém-conquistada pelos entes federativos locais, na forma insculpida no texto constitucional vigente, os colocando a salvo de ingerências do Poder Central, ou mesmo coibindo eventuais ânimos recentralizadores.

Entretanto, a aplicação prática desse dispositivo constitucional revelou a outra face do processo emancipatório, pois, ao invés de se apresentar como uma espécie de grito de liberdade por parte dos entes federativos locais, até então submetidos à tirania de um Poder Central disposto a esvaziar qualquer intento autonômico, a disseminação da criação de novos Municípios por todas as regiões de nosso País foi fortemente motivada pelo recebimento do repasse de receitas oriundas das outras esferas governamentais, portanto, em nada identificável com a consolidação de uma verdadeira autonomia descentralizada.

A conseqüência imediata dessa mobilização das localidades para angariar recursos por intermédio das emancipações foi o avassalador fenômeno de criação de Municípios ocorrido nos últimos anos, em grande medida, impulsionado pela vigência da atual Constituição Federal, uma vez que o nosso País contava com apenas 3.974 Municípios instalados em 1980, número este elevado à marca de $5.561 \mathrm{em} 2000^{25}$, isto é, um crescimento de quase quarenta por cento no curto intervalo de duas décadas.

Nesse sentido, tal mudança de competência legislativa para o âmbito estadual apresentou-se totalmente inconveniente, pois os requisitos essenciais à emancipação municipal, constantes das respectivas legislações estaduais, se mostraram pífios, sendo muito freqüente a inexistência de exigências de caráter financeiro para a efetivação da emancipação, o que por si só é contraditório, uma vez que não se pode conceber que um ente federativo seja autônomo, de fato, se ele não tiver recursos compatíveis com o exercício de suas atribuições.

Ademais, no referido período correspondente ao "boom" emancipatório não houve um aumento substancial na arrecadação das receitas públicas, assim como não se constatou um aumento do Produto Interno Bruto (PIB) compatível com a criação de tantas novas entidades subnacionais. ${ }^{26}$

\footnotetext{
${ }^{24}$ O constituinte originário de 1988 assim estabeleceu, no $\S 4^{\circ}$ de seu art. 18: “A criação, a incorporação, a fusão e o desmembramento de Municípios preservarão a continuidade e a unidade histórico-cultural do ambiente urbano, far-se-ão por lei estadual, obedecidos os requisitos previstos em lei complementar estadual, e dependerão de consulta prévia, mediante plebiscito, às populações diretamente interessadas" (grifos nossos).

${ }^{25}$ Cf. LORENZETTI, Maria Sílvia Barros. Criação, incorporação, fusão e desmembramento de Municípios. Disponível em: < http://www.camara.gov.br >. Acesso em: 28 set. 2007.

${ }^{26}$ Cf. GOMES, Gustavo Maia; MACDOWELL, Maria Cristina. Descentralização política, federalismo fiscal e criação de Municípios: o que é mau para o econômico nem sempre é bom para o social. Disponível em: <
} 
Isso significa dizer que o "bolo arrecadatório" se tornou cada vez mais exíguo e insuficiente ao atendimento dos anseios da coletividade em geral, em outras palavras, a federação brasileira padeceu a cada emancipação municipal levada a efeito sem uma criteriosa avaliação de sua viabilidade, resultante da permissividade das legislações estaduais, em particular, quanto ao aspecto econômico-financeiro.

Prova disso é que o Rio Grande do Sul, na qualidade de Estado-membro da federação brasileira que mais promoveu emancipações no período compreendido entre 1988 e 2000 (um total de 253, o que corresponde a quase $20 \%$ de todos os novos Municípios criados após a vigência da atual Constituição Federal), ${ }^{27}$ tem uma legislação vigente que não faz qualquer exigência específica de cunho financeiro quanto aos requisitos emancipatórios. ${ }^{28}$

O mesmo se diga a respeito de São Paulo, Estado-membro que também teve uma proliferação municipalista destacada após a vigência da Constituição Federal de 1988, saltando de 572 para 645 Municípios instalados, ${ }^{29}$ ressaltando que a sua legislação vigente em matéria de emancipação municipal também não faz referência à observância de requisitos financeiros. ${ }^{30}$

Desse modo, a criação desenfreada de Municípios brasileiros encontrou sua principal fonte motivacional no caminho "fácil" da aquisição de meios materiais sem qualquer contrapartida, ou seja, de maneira veementemente clientelista. Processo esse que, a nosso ver, deveria se pautar principalmente no atendimento de requisitos de índole financeira, até mesmo pelo fornecimento de critérios mais técnicos e objetivos para a apuração da viabilidade do candidato a ente federativo autônomo, ao invés da resolução da questão ser entregue ao sabor dos interesses políticos dominantes em cada localidade.

http://www.federativo.bndes.gov.br >. Acesso em: 01 fev. 2002.

${ }^{27}$ Cf. TOMIO, Fabrício Ricardo de Limas. Federalismo, Municípios e decisões legislativas: a criação de Municípios no Rio Grande do Sul. Revista de Sociologia e Política, n. 24, p. jun. 2005. p. 124.

${ }_{28}$ Vide as leis complementares gaúchas n. 9.070/90 e n. 9.089/90, que fixam como requisitos à emancipação municipal os seguintes: a) população mínima de mil e oitocentos eleitores ou de cinco mil habitantes; b) cento e cinqüenta casas ou prédios no núcleo urbano; c) condições reais de desenvolvimento; d) cem eleitores da área emancipanda que possam formar uma comissão emancipacionista; e) plebiscito que registre o comparecimento de, no mínimo, cinqüenta por cento dos referidos eleitores ou habitantes; f) sanção do Governador ao plebiscito.

${ }^{29}$ Cf. BRAGA, Roberto; PATEIS, Carlos da Silva. Criação de Municípios: uma análise da legislação vigente no Estado de São Paulo. Disponível em: < http://www.rc.unesp.br/igce >. Acesso em: 28 set. 2007.

${ }^{30}$ Vide a Lei Complementar paulista n. 651/90, que estabelece os seguintes requisitos à emancipação municipal: a) plebiscito de iniciativa de, no mínimo, cem eleitores domiciliados na área emancipanda; b) a área emancipanda deve ser distrito a mais de dois anos; c) possuir pelo menos mil eleitores em sua área territorial; d) possuir solução de continuidade de, no mínimo, três quilômetros entre seu perímetro urbano e o do Município de origem (exceto em regiões metropolitanas ou aglomerados urbanos); e) não interromper a continuidade territorial do Município de origem e preservar a continuidade histórico-cultural do ambiente urbano; f) não causar perda de qualquer dessas condições ao Município de origem. 
Nova mudança significativa no cenário das emancipações locais de nosso País se deu com o advento da Emenda Constitucional n. 15, de 12 de setembro de 1996, que conferiu nova redação ao mencionado $\S 4^{\circ}$ do art. 18 , surgindo como uma espécie de reação do constituinte derivado à ocorrência do turbilhão emancipatório acima descrito.

Parte do problema foi solucionado com a nova dicção do texto constitucional referente à matéria, ${ }^{31}$ no sentido de que a esfera federal ficou com a competência legal de determinar o período emancipatório (Lei Complementar federal), bem como a realização de um estudo quanto à viabilidade municipal (Lei Ordinária federal), o que significou ao menos uma paralisação daquele processo irracional de emancipações locais.

Entretanto, a nosso juízo, essa Emenda Constitucional não solucionou o principal problema, é dizer, a competência para a fixação dos requisitos emancipatórios continuou a ser da esfera estadual, mesmo com todo o histórico de fragilidade dos critérios exigidos à emancipação, ainda constantes das legislações estaduais que regem o tema.

Por essa razão, quando o Congresso Nacional conferir eficácia plena à Emenda Constitucional mencionada, por meio da sua regulamentação ainda pendente, haverá enorme probabilidade de acontecer um novo surto emancipatório, com conseqüências nefastas à Federação brasileira, empobrecida progressivamente pela repartição de disponibilidades materiais que se apresentam cada vez mais insuficientes.

Até porque, a emancipação municipal deveria resultar do crescimento populacional e do desenvolvimento econômico locais, ao contrário do que se pode verificar ao analisarmos o processo emancipatório brasileiro, pois, dentre os 1.405 Municípios criados no período compreendido entre 1984 e 1996, nada menos que 1.329 $(94,6 \%)$ contavam com populações inferiores a vinte mil habitantes, tendo 735 deles $(52,3 \%)$ menos de cinco mil. Além disso, a média de receita própria dos novos Municípios brasileiros com populações inferiores a vinte mil e a cinco mil habitantes corresponde, respectivamente, a $12,3 \%$ e a $8,9 \%$ do total arrecadado para cada exercício, sendo o restante proveniente de transferências fiscais, principalmente decorrentes do Fundo de Participação dos Municípios (FPM). ${ }^{32}$

Essa situação se agrava diante da constatação de que, à época, somente 2,2\% da população brasileira vivia em Municípios de até cinco mil habitantes e, mesmo considerando a faixa populacional de até vinte mil habitantes, ainda assim os números

\footnotetext{
${ }^{31}$ A redação do $\S 4^{\circ}$ do art. 18 da Constituição Federal passou a ser a seguinte: "A criação, a incorporação, a fusão e o desmembramento de Municípios, far-se-ão por lei estadual, dentro do período determinado por lei complementar federal, e dependerão de consulta prévia, mediante plebiscito, às populações dos Municípios envolvidos, após divulgação dos Estudos de Viabilidade Municipal, apresentados e publicados na forma da lei" (grifos nossos).

${ }^{32}$ Cf. GOMES, Gustavo Maia; MACDOWELL, Maria Cristina. Descentralização politica, federalismo fiscal e criação de Municípios: o que é mau para o econômico nem sempre é bom para o social. Disponível em: $<$ http://www.federativo.bndes.gov.br >. Acesso em: 01 fev. 2002.
} 
mostravam que apenas 19,6\% da população brasileira vivia em Municípios pequenos. Sem falar que os pequenos Municípios não são necessariamente os mais pobres, visto que, na média nacional, os habitantes dos Municípios de até cinco mil habitantes ocuparam todos os níveis de variação de renda per capita, estando concentrados principalmente nos níveis 5, 6, 7 e 8 (em uma escala de 0 a 10), daí não se sustentar o argumento de que há um caráter redistributivo na concessão de maiores repasses aos "micromunicípios", caindo por terra a justificativa de que estes últimos devem ser beneficiados pelas transferências fiscais. ${ }^{33}$

Os mencionados dados nacionais globais são congruentes com o que se depreende da análise particular dos processos emancipatórios levados a efeito nas esferas estaduais. Por exemplo, no Estado de São Paulo, 68,48\% dos Municípios criados entre 1990 e 2000 tinham menos de cinco mil habitantes, assim como 83,46\% deles contavam com menos de dez mil habitantes. Quanto à capacidade arrecadatória, a média de receita própria dos Municípios paulistas emancipados era de 3,22\% para aqueles com populações de até cinco mil habitantes, e de 7,74\% para aqueles com populações de até dez mil habitantes. Ademais, $86 \%$ dos que tinham até cinco mil habitantes encontraram no Fundo de Participação dos Municípios a sua principal fonte de receita (média de $42,81 \%$ do total arrecadado em 2000). ${ }^{34}$

Assim sendo, as estatísticas mostram que a ampliação na criação de entes federativos locais no Brasil significou, essencialmente, criar Municípios de pequena população e de grande dependência econômica das transferências fiscais, conforme lhes foi facultado pelo próprio texto constitucional vigente. Até porque, o aparato burocrático criado para o funcionamento das novas Administrações Municipais, com seus quadros funcionais, consome a maior parte das receitas repassadas pelas outras esferas governamentais, tornando a prestação dos serviços públicos locais proporcionalmente mais onerosa aos contribuintes.

A nosso juízo, esse quadro de hipossuficiência crônica dos Municípios se deve tanto à permissividade das legislações estaduais, que não fixam critérios financeiros com vistas à emancipação, na forma preconizada pelo regime constitucional anterior, quanto à vigência, no atual regime constitucional, de critérios para a efetivação de transferências fiscais que se mostraram ineficientes na promoção da verdadeira autonomia financeira dos entes federativos locais.

Nessa senda, os novos Municípios emancipados, até mesmo pelos seus baixos índices populacional e de receitas próprias, têm características eminentemente rurais, ao mesmo tempo que as suas principais fontes potenciais de receita se relacionam

\footnotetext{
33 Id. Ibid.

${ }^{34}$ Cf. BRAGA, Roberto; PATEIS, Carlos da Silva. Criação de Municípios: uma análise da legislação vigente no Estado de São Paulo. Disponível em: < http://www.rc.unesp.br/igce >. Acesso em: 28 set. 2007.
} 
à ocorrência de hipóteses de incidência tributárias com perfil arrecadatório mais afinado à infra-estrutura urbana, tais como os impostos que recaem sobre a propriedade predial e territorial urbana (IPTU), os serviços de qualquer natureza (ISS), a propriedade de veículos automotores (IPVA) e as operações relativas à circulação de mercadorias e prestação de serviços (ICMS).

Também o Fundo de Participação dos Municípios, previsto no art. 159, I, b, da Constituição Federal, determina que a União deve entregar aos Municípios vinte e dois e meio por cento do que ela arrecadar a título de impostos sobre a renda e proventos de qualquer natureza (IR), bem como sobre os produtos industrializados (IPI). Entretanto, estes tributos não são substancialmente arrecadados nas pequenas municipalidades, ao invés disso, são recolhidos quase que em sua totalidade junto a Municípios com mais de cem mil habitantes, de modo que estes são os grandes responsáveis pela constituição de um Fundo que servirá de principal fonte financiadora daqueles. ${ }^{35}$

Desse modo, cada "micromunicípio" emancipado é mais um cliente em potencial do federalismo fiscal nacional, pois há o desestímulo generalizado à implementação arrecadatória, visto que os Municípios de maior contingente populacional acabam transferindo grande parte do produto de seu esforço fiscal, gratuitamente, aos de menor contingente populacional, os quais, por sua vez, passam a contar sempre mais com tal "ajuda".

Além disso, a forma de recebimento dos valores que compõem o Fundo de Participação dos Municípios, consoante ao disposto no art. 91 da Lei n. 5.172, de 25 de outubro de 1966 (Código Tributário Nacional - CTN), é responsável pela ocorrência de uma grave distorção, uma vez que foi fixada uma quota mínima para o recebimento de tais transferências, pois há um único coeficiente de repasse de valores para todos aqueles Municípios que não sejam capitais de seus Estados-membros e que contabilizem até 10.188 habitantes. ${ }^{36}$ Isso quer dizer que quase todas as novas emancipações levadas a efeito nos últimos anos foram abrangidas por esta regra, que, aliás, forneceu fundamento jurídico e fático aos pleitos emancipatórios das mais recônditas localidades.

Diante desse quadro geral vislumbrado a partir da descentralização fiscal brasileira, em particular, observado o processo de emancipação dos entes federativos locais, podemos dizer que ele não foi o resultado da consolidação da forma democrática de Governo, mas, antiteticamente, uma conseqüência das tolerantes legislações estaduais

\footnotetext{
${ }^{35}$ Cf. GOMES, Gustavo Maia; MACDOWELL, Maria Cristina. Descentralização política, federalismo fiscal e criação de Municípios: o que é mau para o econômico nem sempre é bom para o social. Disponível em: < http://www.federativo.bndes.gov.br >. Acesso em: 01 fev. 2002.

36 Vide Decisão Normativa do Tribunal de Contas da União (TCU), n. 09, de 29 de novembro de 1995, bem como as leis complementares n 62, de 28 de dezembro de 1989, e nº 91, de 22 de dezembro de 1997.
} 
vigentes em nosso País, haja vista estarem elas direcionadas à percepção do maior montante possível de repasses federais aos novos Municípios criados.

No mesmo sentido, o advento desse processo emancipatório também teve sua origem estreitamente ligada não-só à estabilização, mas também à ampliação das transferências fiscais aos novos Municípios criados, com destaque para o recebimento de uma quota mínima do Fundo de Participação dos Municípios, sem o oferecimento de nenhuma contrapartida, ainda que estes entes federativos locais se apresentassem desprovidos de qualquer infra-estrutura urbana ou sustentabilidade econômica.

Em suma, a despeito da constante limitação das fontes de recursos que movem a engrenagem federativa pátria, foram beneficiados os poucos que residem em pequenos Municípios, e que não são necessariamente os mais pobres, em detrimento dos muitos que residem nos demais, ocasionando uma situação de escassez geral e de fartura localizada, sendo esta última consumida, em larga escala, na manutenção do novo aparato administrativo criado, ao invés de promover investimentos de cunho social.

No mais, embora haja o apelo à democracia direta no emancipacionismo nacional, por meio da consulta prévia plebiscitária, de acordo com o mencionado $\S 4^{\circ}$, do art. 18 constitucional, é clara sua dicção no sentido de que somente serão ouvidas as populações dos Municípios envolvidos, ou seja, haverá a oitiva apenas daquela ínfima minoria local de potenciais ganhadores com tal processo, enquanto a absoluta maioria de perdedores, disseminados por toda a extensão da federação brasileira, permanecerão silenciados.

A prevenção de toda essa problemática que envolve a "economia política da secessão", na expressão utilizada por Cláudio Djissey Shikida, ${ }^{37}$ a nosso ver, demanda o urgente aprimoramento do ordenamento jurídico brasileiro, principalmente em sua vertente financeira, a fim de que seja preservado o potencial democrático da descentralização fiscal, em última instância, pautando-se na consecução da autonomia financeira local.

Ao encontro desse entendimento, enorme contributo seria o da fixação de critérios jurídicos mais rígidos que aqueles vigentes nas legislações estaduais atinentes às emancipações municipais, especialmente, estabelecendo requisitos que levem em conta a infra-estrutura urbana e a efetiva sustentabilidade econômica, pois é de extrema importância a apuração da verdadeira capacidade arrecadatória dos candidatos a ente federativo autônomo.

Para tanto, é imperativo que requisitos de índole financeira sirvam de norte à vindoura regulamentação federal dos "Estudos de Viabilidade Municipal”, assim referidos no $\S 4^{\circ}$, do art. 18 da Constituição Federal, tornando exeqüível a emancipação municipal

\footnotetext{
37 SHIKIDA, Cláudio Djissey. A economia politica da emancipação de Municípios em Minas Gerais. Disponível em: < http://www.stn.fazenda.gov.br >. Acesso em: 24 set. 2007.
} 
somente se comprovada a aptidão da localidade para a obtenção de receitas próprias, de modo a impedir a criação de novos entes federativos com status autonômico, quando em realidade, desde sua gênese, são notórios clientes de nosso federalismo fiscal.

Como proposta de critério financeiro essencial, a ser incluído na futura regulamentação federal da matéria, sugerimos que a emancipação municipal só poderia ser levada adiante, sendo classificada como viável, se a localidade candidata tiver arrecadado, no exercício financeiro anterior à iniciativa emancipatória, um montante de receitas próprias superior à estimativa de recebimento do repasse exclusivo da sua quota correspondente, via Fundo de Participação dos Municípios, em caso de emancipação.

Nesses moldes, a regulamentação federal implementaria, de forma significativa, a avaliação dos pleitos emancipatórios, uma vez que o potencial autonômico de cada localidade seria determinado pelo resultado da análise comparativa de ambos volumes arrecadatórios (receita própria de um lado e estimativa de transferência da quota FPM do outro), ou seja, a observância deste critério financeiro serviria de parâmetro técnico e objetivo à verificação da viabilidade ou inviabilidade municipal.

Ressaltando que a adoção de tal critério financeiro teria impedido a emancipação de 90,4\% dos Municípios paulistas agraciados, entre 1990 e 2000, com a condição de ente federativo autônomo, visto que apenas sete deles, de um total de setenta e três, tinham em suas fontes próprias de receita um contingente maior que o repasse exclusivo da quota proveniente do Fundo de Participação dos Municípios. ${ }^{38}$

Também deveria haver uma alteração legal na forma de distribuição das quotas do Fundo de Participação dos Municípios, pois a transferência dos recursos que o compõem segue um critério de enquadramento municipal em faixas populacionais, o que vem gerando consideráveis distorções no processo emancipatório brasileiro.

Isso porque a legislação vigente (art. 91 do Código Tributário Nacional e Decisão Normativa n. 09, de 29 de novembro de 1995, do Tribunal de Contas da União), fixa quotas individuais mínimas de recebimento, com base no número de habitantes de cada Município emancipado, devidamente apurado em recenseamento demográfico. De modo que, todo Município que não seja capital de Estado-membro e que possua até 10.188 habitantes fará jus a um coeficiente mínimo de repasse (coeficiente individual 0,6), relativo à distribuição de $90 \%$ do valor constante do Fundo de Participação dos Municípios (FPM).

Como antes demonstrado, a grande maioria das recentes emancipações municipais ocorridas em nosso País foi levada a efeito com populações inferiores a dez mil habitantes, para ser mais preciso, dos 1.405 Municípios instalados entre 1984 e

\footnotetext{
${ }^{38}$ Cf. BRAGA, Roberto; PATEIS, Carlos da Silva. Criação de Municípios: uma análise da legislação vigente no Estado de São Paulo. Disponível em: < http://www.rc.unesp.br/igce >. Acesso em: 28 set. 2007.
} 
1996, nada menos que $1.095(78 \% \text { do total })^{39}$, o que permite constatar que a instituição de uma quota mínima de repasse dos valores que compõem o FPM, com base em uma faixa populacional de até 10.188 , é o mesmo que instituir um único coeficiente à quase totalidade dos emancipados.

Assim sendo, o estabelecimento do repasse mínimo de recursos, provenientes deste Fundo, serviu de enorme atrativo às emancipações, não raro, das localidades mais insustentáveis do ponto de vista econômico-financeiro, as quais, inclusive, encontraram extrema facilidade na consecução de seus intentos, em face das permissivas legislações estaduais então vigentes.

A abolição das faixas populacionais, e do seu respectivo coeficiente mínimo de recebimento, a nosso juízo, também se presta à coibição das inviáveis candidaturas à emancipação, bastando que seja adotado um outro critério legal para os repasses do FPM, doravante fundado na transferência per capita de suas quotas correspondentes.

Até porque, a simples substituição legal da transferência de recursos por faixa populacional pela transferência de recursos per capita, arrefeceria muito o propósito emancipatório dos habitantes e políticos daquelas localidades caracterizadas pelo exíguo contingente populacional, tendo em vista que o repasse da quota do FPM seria muito pequeno para se fazer frente ao atendimento dos anseios populares locais e, ao mesmo tempo, manter as estruturas burocráticas da nova Prefeitura a ser instalada.

Portanto, seria desferido mais um forte golpe nas intenções clientelistas que, porventura, pudessem permear o ideário emancipacionista, uma vez que o seu principal elemento motivacional, isto é, o cômodo repasse financeiro sem qualquer contrapartida, já não seria tão condizente com os interesses restritos ao âmbito meramente local.

As mencionadas mudanças em nossa ordem jurídica, voltadas à apuração da verdadeira capacidade das localidades para a obtenção de receitas próprias, assim como à racionalização das transferências fiscais do FPM, podem significar um grande avanço em matéria de consecução da autonomia financeira local neste País.

Daí a necessidade premente de aperfeiçoamento de nosso ordenamento, com o intuito de que prevaleça, de fato, a autonomia financeira local, ao invés da instigação institucionalizada ao clientelismo subnacional. O que resultaria na ampliação do cânone democrático, pois a gestão das finanças governamentais de uma localidade verdadeiramente autônoma, em seu aspecto econômico-financeiro, não só possibilita, mas também incita o debate público em torno do substrato material existente em cada circunscrição territorial,

\footnotetext{
${ }^{39}$ Cf. GOMES, Gustavo Maia; MACDOWELL, Maria Cristina. Descentralização politica, federalismo fiscal e criação de Municípios: o que é mau para o econômico nem sempre é bom para o social. Disponível em: < http://www.federativo.bndes.gov.br >. Acesso em: 01 fev. 2002.
} 
servindo a participação popular de legítima fonte propositiva das políticas públicas que deverão ser implementadas com tais recursos descentralizados.

Até porque, o controle social da atividade financeira estatal se torna difuso em ambientes comunitários, decorrente da maior proximidade entre cidadãos e gestores públicos, uma vez que os atos e as decisões governamentais, atinentes à aplicação dos recursos disponíveis, ganham visibilidade com a afirmação da autonomia financeira local, engendrada pela criteriosa descentralização fiscal, a qual seja capaz de promover o equilíbrio, em um contexto federativo, entre as atribuições e os meios materiais de cada ente.

Nesse sentido, é uma exigência democrática que a destinação dos recursos públicos locais seja definida pelas articulações do meio social, ou seja, o processo decisório governamental deve ser o reflexo imediato das preferências comunitárias, inclusive, levando-se em consideração, na maior medida possível, sua compleição hierarquizada.

Dessa forma, o orçamento público local se revela um instrumento hábil ao atendimento desses objetivos, conferindo materialidade aos anseios sociais emanados de cada circunscrição financeira autônoma, pois a participação popular na elaboração e execução orçamentárias lhe atribui o caráter de genuíno processo de decisão coletiva.

São Paulo, janeiro de 2008.

Referências

AFONSO, José Roberto Rodrigues; LOBO, Thereza. Descentralização fiscal e participação em experiências democráticas retardatárias. Disponível em: < http://www.federativo. bndes.gov.br $>$. Acesso em: 30 jan. 2002.

ASSONI FILHO, Sérgio. A lei de responsabilidade fiscal e o federalismo fiscal. In: CONTI, José Maurício (org.). Federalismo fiscal. São Paulo: Manole, 2004.

BALEEIRO, Aliomar. Uma introdução à ciência das finanças. 4. ed. Rio de Janeiro: Forense, 1968.

BARACHO, José Alfredo de Oliveira. Teoria geral do federalismo. Belo Horizonte: FUMARC/ UCMG, 1982.

BOBBIO, Norberto. O futuro da democracia: uma defesa das regras do jogo. Tradução de Marco Aurélio Nogueira. 7. ed. São Paulo: Paz e Terra, 2000.

BRAGA, Roberto; PATEIS, Carlos da Silva. Criação de Municípios: uma análise da legislação vigente no Estado de São Paulo. Disponível em: < http://www.rc.unesp.br/igce > Acesso em: 28 set. 2007.

BREMAEKER, François E. J. Pacto federativo com justiça fiscal. In: Instituto Brasileiro de Administração Municipal, n. 38, fev. 2002. 
CAMARGO, Guilherme Bueno de. A guerra fiscal e seus efeitos: autonomia x centralização. In: CONTI, José Maurício (org.). Federalismo fiscal. São Paulo: Manole, 2004.

CLUZEL, Jean. Finances publiques e pouvoir local. Paris: Librairie Générale de Droit et de Jurisprudence, 1980.

COHEN, Jean L.; ARATO, Andrew. Sociedad civil y teoría política. Tradução de Roberto Reyes Mazzoni. Ciudad del México: Fondo de Cultura Económica, 2000.

CONTI, José Maurício. Federalismo fiscal e fundos de participação. São Paulo: Juarez de Oliveira, 2001.

DE JUANO, Manuel. Curso de finanzas y derecho tributario. Rosario: Molachino, 1964. v. 1-3.

DIAS, Solange Gonçalves. Democracia representativa 'versus' democracia participativa: participação popular no plano local e emergência de um novo paradigma democrático. 2001. Dissertação (Mestrado) - Faculdade de Direito, Universidade de São Paulo, São Paulo.

FREITAS, Juarez. O controle social do orçamento público. Revista Interesse Público, n. 11, 2001.

GARCÍA DE ENTERRÍA, Eduardo. Democracia, jueces y control de la administración. 5. ed. Madrid: Civitas, 2000.

GOLDSCHMIDT, Fábio Brun. Críticas à discriminação de rendas tributárias e à federação brasileira. Revista Tributária e de Finanças Públicas, v. 8, n. 35, nov./dez. 2000.

GOMES, Gustavo Maia; MACDOWELL, Maria Cristina. Descentralização política, federalismo fiscal e criação de Municípios: o que é mau para o econômico nem sempre é bom para o social. Disponível em: <http://www.federativo.bndes.gov.br>. Acesso em: 01 fev. 2002.

GROTTI, Dinorá Adelaide Musetti. Desafios da democratização da gestão local: a formulação do orçamento participativo. In: GARCIA, Maria. (Coord.). Democracia, hoje: um modelo político para o Brasil. São Paulo: Instituto Brasileiro de Direito Constitucional, 1997.

GUIMARÃES NETO, Leonardo. Desigualdades e politicas regionais no Brasil: caminhos e descaminhos. Disponível em: <http://www.federativo.bndes.gov.br>. Acesso em: 18 fev. 2002.

LONGO, Carlos Alberto; TROSTER, Roberto Luis. Economia do setor público. São Paulo: Atlas, 1993.

LORENZETTI, Maria Sílvia Barros. Criação, incorporação, fusão e desmembramento de Municípios. Disponível em: <http://www.camara.gov.br>. Acesso em: 28 set. 2007.

LUCAS, John Randolph. Democracia e participação. Tradução de Cairo Paranhos Rocha. Brasília: Editora Unb, 1985.

MADDICK, Henry. Democracia, descentralização e desenvolvimento. Tradução de Ruy Jungmann. Rio de Janeiro: Forense, 1966. 
MAGALHÃES, José Luíz Quadros de. O poder local no Brasil: a alternativa da democracia participativa. Disponível em: <http:// www.cadireito.com.br>. Acesso em: 18 set. 2005.

MARQUES JÚNIOR, Liderau dos Santos; PORTO JÚNIOR, Sabino da Silva; FLORISSI, Stefano. Processo orçamentário no Estado do Rio Grande do Sul: uma proposta alternativa de participação popular na elaboração e fiscalização do orçamento público estadual. Disponível em: $<$ http://www. ie.ufrj.br>. Acesso em: 30 set. 2007.

MILL, John Stuart. Considerações sobre o governo representativo. Tradução de Manoel Innocêncio de Lacerda Santos Júnior. Brasília: Editora Unb, 1981.

MONTESQUIEU. Do espírito das leis. Tradução de Fernando Henrique Cardoso. São Paulo: Difusão Européia do Livro, 1962. v. 1 e v. 2.

MOREIRA NETO, Diogo de Figueiredo. Direito da participação política. Rio de Janeiro: Renovar, 1992.

MORSELLI, Emanuele. Compendio di scienza delle finanze. 21. ed. Padova: CEDAM, 1952.

OLIVEIRA, Régis Fernandes de. Curso de direito financeiro. São Paulo: Revista dos Tribunais, 2006.

REZENDE, Fernando. Federalismo fiscal: novo papel para Estados e Municípios. Disponível em: $<$ http: //www.federativo.bndes.gov.br>. Acesso em: 30 jan. 2002.

SAMPAIO DÓRIA, Antônio Roberto. Discriminação de rendas tributárias. São Paulo: Bushatsky, 1972.

SANTOS, Boaventura de Sousa. Orçamento participativo em Porto Alegre: para uma democracia redistributiva. In: SANTOS, Boaventura de Sousa (Org.). Democratizar a democracia: os caminhos da democracia participativa. Rio de Janeiro: Civilização Brasileira, 2002.

SERRA, José; AFONSO, José Roberto. Federalismo fiscal à brasileira: algumas reflexões. Disponível em: <http://www.federativo.bndes.gov.br>. Acesso em: 30 jan. 2002.

SHIKIDA, Cláudio Djissey. A economia política da emancipação de Municípios em Minas Gerais. Disponível em: <http://www.stn.fazenda.gov.br>. Acesso em: 24 set. 2007.

SILVA, Marcelo Kunrath. Construção da participação popular. Porto Alegre. IFCH/UFRS - Tese de Doutorado, 2001.

TEIXEIRA, Elenaldo Celso. Sociedade civil e participação cidadã no poder local. 1998. Tese (Doutorado) - Faculdade de Filosofia, Letras e Ciências Humanas, Universidade de São Paulo, São Paulo.

TOCQUEVILlE, Alexis de. A democracia na América. Tradução de Eduardo Brandão. São Paulo: Martins Fontes, 1998. 
TOMIO, Fabrício Ricardo de Limas. Federalismo, Municípios e decisões legislativas: a criação de Municípios no Rio Grande do Sul. Revista de Sociologia e Política, n. 24, jun. 2005.

TORRECILLAS RAMOS, Dircêo. O federalismo assimétrico. São Paulo: Plêiade, 1998.

TORRES, Heleno Taveira. La autonomía financiera de los municipios en el derecho brasileño. Revista Argentina de Derecho Tributario, n. 4, out./ dez. 2002. 